\title{
Pequeno Ensaio sobre a Injustiça: memórias secas de um tribunal de segurança nacional
}

\author{
Marcelo Andrade Cattoni de Oliveira ${ }^{1}$ \\ Gustavo Silveira Siqueira ${ }^{2}$
}

\begin{abstract}
Resumo: O presente artigo pretende fazer uma reconstrução da história do Tribunal de Segurança Nacional. Mas a pretensão não é fazer essa reconstrução com aspectos legais apenas, mas utilizar a literatura, nesse caso específico a obra Memórias do Cárcere de Graciliano Ramos, como um caminho para estudar o Tribunal de Segurança Nacional para além das suas normas, para além dos seus julgamentos. A tentativa é demonstrar como a literatura, especialmente nesse caso, pode ser uma fonte de História do Direito e um importante caminho para compreender a percepção da sociedade àquela época sobre o direito e suas instituições.
\end{abstract}

Palavras-chave: Memórias do Cárcere. Tribunal de Segurança Nacional. Direito, História e Literatura.

\begin{abstract}
This article aims a reconstruction of the Brazilian National Security Court' history. But the intention is not to make this reconstruction only based on legal issues, but to use the literature, in this specific case the work of Graciliano Ramos, Memórias do Cárcere, as a way to study the National Security Court beyond its rules and trials. The attempt is to show how the literature, especially in this case, may be a source of Legal History, and an important way to comprehend the society's per ception, at that time, about Law and its institutions.
\end{abstract}

Keywords: Memórias do Cárcere. National Security Court. Law, History and Literature.

1 Possui Mestrado (1997) e Doutorado (1999) em Direito pela Universidade Federal de Minas Gerais. Realizou estágio de pós-doutorado como bolsista da CAPES em Teoria do Direito na Università degli studi di Roma Tre (2008-2009). Professor Associado da Universidade Federal de Minas Gerais. Coordenador do Curso de Bacharelado em Ciências do Estado da Faculdade de Direito da UFMG.E-mail: mcattoni@gmail.com.

2 Mestre e Doutorando em Direito pelo Programa de Pós-graduação em Direito da Universidade Federal de Minas Gerais. Possui pós-graduação em Direito do Estado e em Filosofia Jurídica pela Universidade Estadual de Londrina. Estagiário de Docência com bolsa CAPESREUNI junto ao Bacharelado em Ciências do Estado da Faculdade de Direito da UFMG.E-mail: gsique@yahoo.com.br. 


\section{Introdução}

O Tribunal de Segurança Nacional (TSN) foi um tribunal criado para julgar os inimigos do governo Vargas. A intenção da sua criação era condenar os elementos nocivos ao Estado. Seus julgamentos eram meros teatros, em que a legalidade era utilizada como instrumento da ditadura e da opressão. A tentativa do presente artigo é fazer uma reconstrução da história do Tribunal de Segurança Nacional, visando compreender o regime Vargas, para além da discussão sobre a administração pública, focando a análise no cumprimento e no descumprimento das leis pelo governo (LOEWENSTEIN, 1944). Para tanto, serão trazidos elementos metajurídicos que podem auxiliar em uma melhor compreensão da História do Direito, num diálogo interdisciplinar entre Direito e Literatura. Nesse sentido, a descrição que Graciliano Ramos faz do TSN na obra Memórias do Cárcere é uma forma de compreender, para além da legalidade, como esse Tribunal atuava, julgava e era visto pela sociedade brasileira. Memórias do Cárcere é o relato da violência institucional e de uma sociedade que sofria e tentava se conscientizar frente à ditadura Vargas. É um grito contra as perseguições, torturas, mas, especialmente, é um relato do Brasil, um retrato seco sobre a sociedade, o Estado e suas instituições da época.

\section{Contextualização}

O governo que se instala após a Revolução de 1930 é composto por diversos grupos, entre eles: as velhas oligarquias que participaram do processo e tentavam reconstruir o Estado nos velhos moldes e daqueles grupos ligados ao movimento tenentista que se opunham a essas propostas e apoiavam Getúlio Vargas em seu plano de reforçar o poder central (FAUSTO, 2008, p. 332).

O novo governo dissolve o Congresso Nacional, as Assembléias Legislativas Estaduais e as Câmaras Municipais, destitui os governadores eleitos e nomeia interventores para os Estados-membros. Ao mesmo passo que a Igreja Católica demonstrava apoio ao governo, levando seus 
fiéis também a apoiá-lo, o governo retribuía permitindo, contrariamente às normas constitucionais, o ensino da religião nas escolas públicas (FAUSTO, 2008). A intenção do novo governo era realmente ter o apoio das massas. Isso foi demonstrado também na sua política trabalhista que teve como "objetivos principais reprimir os esforços organizatórios da classe trabalhadora urbana fora do controle do Estado e atraí-la para o apoio difuso do governo" (FAUSTO, 2008). O governo tentou capitanear os sindicados, que deveriam estar ligados ao poder executivo, por meio do recém criado Ministério do Trabalho e de outros órgãos. A liberdade de manifestação é reduzida, em troca são oferecidos os direitos sociais. O Estado unifica-se na pessoa do presidente da República e os interventores, muitos deles participantes do movimento tenentista, não conseguem realizar grandes transformações e acabam entendendo-se com setores das classes dominantes (FAUSTO, 2008), a luta contra as oligarquias precisava de muito mais do que a nomeação de simples interventores nos Estados, era preciso investir em educação, em estruturas básicas, era necessário modernizar o País ${ }^{3}$ cuja a estrutura burocrática ainda mantém privilégios (GODOY, 2008).

\section{O Governo Contra o Povo?}

A Lei n. 38, de 4 de abril de 1935 positivou os crimes contra a ordem política social. ${ }^{4}$ Dentre os tipos penais trazidos por essa lei, pode-se destacar: o artigo $1^{\circ}$ que legislava sobre a tentativa de alteração da Constituição ou da forma de governo por meios violentos - crime praticado por Getúlio em 1937 - e sobre ato de oposição "à reunião ou ao livre funcionamento dos poderes políticos da União" - crime praticado por Getúlio em vários momentos, em especial em 1937 -, o artigo $9^{\circ}$ que criminali-

\footnotetext{
3 Existiu na década de 30 uma preocupação em criar verdadeiras Universidades no Brasil. Destaca-se o trabalho dos Ministros da Educação Francisco Campos (1930-1932) e Gustavo Capanema, (1934-1945) assim como Anísio Teixeira, secretário da Educação.

4 Para uma análise mais detalhada dessa legislação: NUNES, Diego. O percurso dos crimes políticos durante a Era Vargas (1935-1945): do Direito Penal político italiano ao Direito de Segurança Nacional brasileiro. 2010. 246f. Dissertação (Mestrado em Direito) - Faculdade de Direito, Universidade Federal de Santa Catarina, Florianópolis, 2010.
} 
zava a instigação de ato de desobediência coletiva à lei de ordem pública, o artigo 10 que legislava sobre a distribuição de materiais que incitassem a indisciplina, o artigo 11 que positivava a provocação de animosidade entre classes armadas, o artigo 14 que criminalizava a instigação ao ódio entre as classes e o artigo 15 que punia a instigação as classes sociais à luta pela violência. (BRASIL, 1935).

Dessa forma, podem-se dividir os crimes na Lei n. 38 de 1935 da seguinte forma: os crimes praticados impunemente pelo Governo Vargas e seus colaboradores e os tipos penais dirigidos aos opositores do sistema, que frustravam a liberdade de manifestação e a participação política de tais opositores.

Em 1935 é lançado no Rio de Janeiro o manifesto da Aliança Nacional Libertadora - ANL - que buscava a nacionalização das empresas estrangeiras $^{5}$, a reforma agrária, a garantia das liberdades populares ${ }^{6}$ e a constituição de um governo popular (FAUSTO, 2008). A fundação da ANL foi sucedida de tentativas de golpes, dentre eles a Intentona Comunista que levou à prisão de Luiz Carlos Prestes, Olga Benário, Artur Enerst Ewert e sua esposa, sendo esses dois últimos, barbaramente torturados pela polícia do Distrito Federal, que tinha como chefe Filinto Müller, titular de carta branca do Presidente para torturar, prender sem ordem judicial e investigar até membros do governo.

$\mathrm{O}$ ano de 1936 inicia-se com a grande caça às bruxas do governo Vargas. Opositores ou suspeitos de serem opositores do governo são presos indiscriminadamente, sem ordem judicial, sem processo, sem nenhuma formalização de culpa pelo governo. Intelectuais, militares, funcionários públicos, o governo prende sem limites e sem respeito à ordem constitucional de 1934. O disposto no artigo 113 da Constituição que proibia a violação de correspondência, que garantia a liberdade religiosa, filosófica e política, assim como a manifestação do pensamento e a ampla

5 O artigo 131 da Constituição de 1934 já vedava a propriedade de empresas jornalísticas políticas ou noticiosas a sociedades anônimas por ações ao portador e estrangeiros.

6 Muitos deles já garantidos pelo Capítulo II da Constituição de 1934 intitulado "Dos Direitos e das Garantias Individuais", mas que demonstravam-se ineficazes face a força do Estado Getulista. 
defesa, é esquecido pelo próprio governo, que se transforma em um grande violador de direitos constitucionais. (BRASIL, 2001a).

O congresso apavora-se, largava bambo as leis de arrocho - vivíamos de fato numa ditadura sem freio. Esmorecida a resistência, dissolvidos os últimos comícios, mortos ou torturados operários e pequenos-burgueses comprometidos, escritores, e jornalistas a desdizer-se, a gaguejar, todas as poltronices a inclinar-se para a direita, quase nada poderíamos fazer perdidos na multidão de carneiros. (RAMOS, 2008 , p. 30).

O governo Vargas demonstra a sua face mais autoritária e mais contraditória: ao passo que os direitos sociais eram garantidos constitucionalmente junto com as liberdades civis, essas últimas eram constantemente violadas pelo próprio governo. A mesma situação que fundamentou o levante da Coluna Prestes e sustentou ideologicamente o movimento tenentista repetia-se: Constituição inefetiva, violada pelo próprio governo.

A Lei n. 244, de 11 de Setembro de 1936, consagrou a visão autoritária do governo com a criação do Tribunal de Segurança Nacional. Já a Lei n. 136, 14 de dezembro de 1935, tornou mais severa a Lei de crimes políticos sociais: pelo artigo $3^{\circ}$, o Governo pode reformar, por decreto, militares, pelo bem da disciplina e do interesse das forças armadas da União, assim como servidores civis pelo artigo $4^{\circ}$. Ao alvedrio do governo poderiam ser aposentados funcionários públicos que não colaborassem com regime. O governo Vargas buscava fundamento jurídico para as práticas ditatoriais. E mesmo quando não as encontrava, não deixava de agir.

Graciliano Ramos, escritor e, à época, diretor da Instrução Pública de Alagoas, é preso e levado para o Rio de Janeiro. Sem processo, sem acusação, sem julgamento, Graciliano e outros diversos presos "políticos" são simplesmente detidos e encarcerados pelo governo Vargas. As garantias constitucionais são esquecidas, o governo federal viola flagrantemente a Constituição de 1934.

Até nos países inteiramente fascistas ela (a sangueira pública) exigia aparência de legalidade, ainda se receava a opinião pública. 
Entre nós execuções de aparato eram inexeqüíveis: a covardia oficial restringia-se a espancar, torturar prisioneiros, e de quando em quando anunciavam suicídios misteriosos. Isso se aplica a sujeitos mais ou menos comprometidos no barulho de 1935. Mas que diabo tinha eu com ele? Certamente não me pregariam agulhas nas unhas nem me fariam saltar de uma janela de andar alto. Quanto a mim achava-me tranqüilo. E não me recordava de haver piado uma sílaba que ofendesse a autoridade. (RAMOS, 2008, p. 76).

Destinos diferentes têm os presos na Intentona Comunista. Alguns são levados a prisões comuns, outros submetidos a torturas e maus tratos. A expulsão também é uma arma do governo: Olga Benário Prestes e Genny Gleiser, a primeira, mulher de Luiz Carlos Prestes é enviada grávida para os campos de concentração nazista, a segunda, judia, romena e comunista de 17 anos, seguiria o mesmo fim, se não fosse resgatada na França por membros do partido comunista Francês (GODOY, 2008). Luiz Carlos Prestes, um dos líderes do movimento comunista no Brasil, é preso e levado a julgamento pelo TSN.

As revoltas de 1932 e 1935 tinham possibilitado aos novos chefes do Exército, promovidos a partir de 1930, livrar-se dos radicais e outros oposicionistas dentro da corporação. Os novos generais, especialmente Góis Monteiro, o chefe militar de 1930, e Gaspar Dutra, tinham visão do papel do Exército diferente da dos antigos generais e também da dos "tenentes". Para eles, o Exército não devia ser instrumento político dos chefes civis, como era prática na Primeira República, nem fato de revolução social, como queriam os "tenentes". Devia ter o papel de tutelar sobre o governo e a nação. [...] Estes generais foram aliados de Vargas em seu projeto de pôr um fim ao regime constitucional. (CARVALHO, 2008, p. 105).

A oposição reformista dentro do governo Vargas ia perdendo força, os revoltosos e críticos do regime deveriam ser afastados - seja pelos Tribunais, para dar uma aparente legalidade dos julgamentos, seja pelas prisões arbitrárias - e o fortalecimento do Exército seria uma constante. Para tanto, foi necessário não apenas por fim ao regime constitucional de 1934 
em 1937, mas, antes disso, desrespeitar a Constituição de 1934, prática que se tornou comum no governo Vargas.

Aos olhos da Constituição de 1934, o Tribunal de Segurança Nacional poderia ser encarado como um Tribunal de exceção. O Tribunal de Segurança Nacional ${ }^{7}$ (TSN) foi criado pela Lei n. 244 de 11 de Setembro de 1936, posteriormente alterada pela Lei n. 88 de 20 de Dezembro de 1937. O TSN tornou-se o grande instrumento do governo Vargas para o julgamento dos seus inimigos. A composição era de cinco juízes, "nomeados livremente" pelo Presidente da República. ${ }^{8}$

A competência do TSN era julgar crimes contra a segurança externa da República, contra as instituições militares e crimes de "finalidades subversivas das Instituições Políticas e Sociais”, tipos penais criados pelas Leis n. 38 e n. 136 de 1935. Assim, a atuação do TSN era limitada aos crimes previstos nas supracitadas leis e restrita ao estado de guerra.

As alterações de 1937, ainda de forma mais clara, tornam o TSN um tribunal à serviço da ditara Vargas: a limitação à atuação do TSN apenas no estado de guerra foi extinta, podendo, o TSN atuar a serviço do governo Vargas em todo o país e a todo momento. O TSN passou a julgar os crimes contra a existência, a segurança e a integridade do Estado, os crimes contra a estrutura das instituições e os crimes contra a economia popular. A limitação para julgar os casos previstos nas Leis n. 38 e n. 136 de 1935 foi revogada. O TSN com sua competência ampliada poderia julgar tudo e todos. Ele foi o grande instrumento do governo Vargas para condenar seus opositores. Com os tipos penais extremamente abrangentes e sua competência prorrogada, o TSN era a arma de Vargas quando necessitava julgar os opositores. ${ }^{9}$ Vargas criara o seu palco para julgar opositores e dissidentes do seu governo.

7 Uma análise importante dos aspectos doutrinais e legais do TSN é feita por BALZ, Christiano Celmer. O Tribunal de Segurança Nacional: Aspectos legais e doutrinários de um tribunal na Era Vargas (1936-1945). 2009. 228f. Dissertação (Mestrado em Direito) Faculdade de Direito, Universidade Federal de Santa Catarina, Florianópolis, 2010.

8 A Lei n. 88, de 20 de dezembro de 1937, alterou a composição do TSN para seis Juízes.

9 Outro fator interessante: as sentenças do TSN eram irrecorríveis e não suscetíveis de embargos, por força do artigo 10 da Lei n. 88 de 1937. 
O mundo se tornava fascista. Num mundo assim, que futuro nos reservariam? Provavelmente não havia lugar para nós, éramos fantasmas, rolaríamos de cárcere em cárcere, findaríamos num campo de concentração. Nenhuma utilidade representávamos na ordem nova. (RAMOS, 2008, p. 160-161).

\section{Os Teatros e os Tribunais}

Num quarto de hora a prisão se mudou em teatro; íamos assistir uma comédia.

$[\ldots]$

Não se reconhecia o Tribunal Especial, cópia do fascismo. (RAMOS, 2008, p. 646 e 641).

Prestes foi julgado pelo TSN. No dia do seu julgamento, o Tribunal se reuniu no quartel da Polícia Especial (MORAES; VIANA, 1997). Recusando os advogados nomeados, o capitão da esperança discursou por duas horas, denunciando, como em outras vezes, as torturas submetidas pelos colegas, assim como as condições da prisão. Como não existiam acusações formais contra Prestes, foram "criadas" duas: deserção do Exército em 1924 e o assassinato de Elsa Fernandes, um crime comum, que teoricamente deveria ser julgado pela justiça estadual, mas foi julgado pelo TSN. Pouco importavam as provas, os documentos ou a acusação, Prestes seria condenado. (MORAES; VIANA, 1997). ${ }^{10}$

A critica policial era tão estúpida que julgava a produção artística não pelo conteúdo, mas pelo nome do autor.

[...]

E meia-volta: andar para o sul, depois de ter andando para o norte. Ausência de interrogatório, nenhum vestígio de processo. Por que se comportavam daquele jeito? Pareciam querer apenas demons-

\footnotetext{
10 Segundo Prestes as duas acusações eram falsas. Ele teria pedido baixa do Exército antes de unir-se ao movimento de 1924 e não teria mandado matar a comunista Elsa Fernandes. Mesmo assim, Prestes foi condenado a 45 anos de prisão.
} 
trar-nos que podiam deixar-nos em repouso, em seguida enviar-nos para um lado ou para outro. ( , 2008, p. 77 e 95).

Em Memórias do Cárcere Graciliano descreve as mazelas da prisão, assim como a convivência com diversos presos políticos (RAMOS, 2008). Graciliano foi levado para a casa de detenção no Rio de Janeiro, após a viagem do nordeste até o Rio no porão do Navio Manaus com diversos prisioneiros. Foi defendido por Sobral Pinto, que tentou, inutilmente, protocolar habeas corpus no TSN em favor do escritor alagoano:

[...] a petição lembrava ao TSN que Graciliano não havia sido acusado de crime algum, e exigia que o TSN promovesse, imediatamente, as providencias para esclarecer a situação de presos como Graciliano, que nunca deram mostras de participar de movimentos subversivos. (DULLES, 2001, p. 115).

O TSN simplesmente não respondeu ao pedido.

Sem processo, sem acusação, Graciliano é simplesmente liberado em janeiro de 1937, portanto dez meses antes do golpe do Estado Novo e da outorga da Carta autoritária, de 10 de novembro.

Paralelamente ao TSN, cabe lembrar que o Supremo Tribunal Federal era outra instância em que os opositores do governo eram julgados. Para José Murilo de Carvalho (apud GODOY, 2008, p. 11), "a Suprema Corte da Era Vargas apegou-se ao formalismo e não se opôs à institucionalização do combate aos inimigos do regime”. Foi no STF onde vários habeas corpus foram protocolados em defesa das liberdades e garantias constitucionais dos presos políticos.

Contra Olga Benário Prestes não pesava nenhuma acusação formal. Ela foi expulsa ${ }^{11}$ do Brasil. Seu caso é extremamente singular. O objeto do seu habeas corpus, protocolado junto ao Supremo Tribunal Federal, era para que a mesma continuasse presa no Brasil: "pedia-se para que a paciente permanecesse encarcerada, pretendendo-se com a negação da li-

11 Expulsa por ser considerada nociva ao Brasil. Ainda alega-se que Olga teria sido deportada, por pedido do governo de Adolf Hitler. 
berdade, garanti-la" (GODOY, 2008, p. 49). O desejo do governo Vargas é que Olga fosse simplesmente expulsa do país e entrega à Alemanha Nazista, o que significaria uma pena de morte para uma judia comunista, já procurada por crimes em Berlim. Heitor Lima, seu advogado, lutava para que Olga não fosse expulsa e que fosse julgada. Nem a gravidez de Olga sensibilizou os Ministros.

Alegando que o artigo $2^{\circ}$ do Decreto n. 702 de 21 de Março de 1936 suspendia a garantia constitucional do habeas corpus o STF não toma conhecimento do pedido (GODOY, 2008). O grande defensor da Constituição diz que esta poderia ser limitada por um decreto-lei do governo Vargas. Ficava clara a submissão do Poder Judiciário aos desejos da ditadura. O Judiciário não era o garantidor de direitos, mas sim um local de condenação dos opositores do governo.

Presa pela polícia política, o paradeiro de Genny Gleiser era desconhecido. Estudante, comunista, com apenas 17 anos, sua família conseguiu que a Câmara Federal fizesse moções de protesto, cobrando do Ministro da Justiça a localização e a existência ou não de processo contra a mesma (GODOY, 2008). A discussão chegou ao Supremo Tribunal Federal, e o Ministro da Justiça Vicente Ráo informou que Genny estava presa na cadeia pública da capital e que seria expulsa por "sua atividade como propagandista de idéias subversivas" (GODOY, 2008, p. 95). Em favor de Genny, foi protocolado pedido de habeas corpus junto ao Supremo Tribunal Federal, mas:

A Suprema Corte entendeu que Genny era estrangeira e nociva à ordem pública, o que justificaria a legalidade do decreto de expulsão. Invocou-se que eventuais maus tratos deveriam ser discutidos com as autoridades responsáveis. [...] Naquele contexto de luta contra o comunismo o Supremo Tribunal Federal entendeu que se fazia justiça com a expulsão de Genny. (GODOY, 2008, p. 95).

Jamais o Supremo garantiria o direito de um inimigo nocivo ao Estado. Mais uma vez o Poder Judiciário afiançava a ditadura Vargas e expulsava do país pessoas por convicções políticas ou ideológicas. Genny foi expulsa e enviada para Alemanha Nazista. 
Certamente nos atribuíam culpas graves; na melhor das hipóteses, éramos levianos e desastrados. E o pior é que nos sentíamos infratores, éramos levados a admitir isso. Sinais intempestivos de compaixão, simples referência ao ambiente sórdido, à horrível miséria, mais nos reforçariam a certeza. Tínhamos delinqüido, sem dúvida. Muitas daquelas criaturas ignoravam que delito lhes imputavam. $\mathrm{Na}$ verdade não imputavam: mantinham-nas em segregação, e isto devia bastar para convencê-las. Com o andar do tempo, chegariam a dar razão à nova justiça. Ninguém iria prendê-las e maltratá-las sem motivo. (RAMOS, 2008, p. 118-119).

Em 1938 o Decreto-Lei n. 428, de 16 de maio, dispôs sobre o processo dos crimes contra ordem política e social e o artigo 11 chamava especial atenção: ele facultava ao presidente do TSN, após sessão secreta de votação dos juízes, proclamar a sentença, desde que não houvesse inconveniente para a Justiça. O que fosse inconveniente para a Justiça o artigo silencia. $\mathrm{O}$ fato é que tal artigo parece ser mais uma artimanha para que o juiz presidente pudesse suspender a publicação da decisão, após cessarem os inconvenientes para a Justiça ou até que os votos tornassem-se condizentes com a conveniência, com o anseio do governo.

A Constituição de 1937 e a legislação posterior foram apenas uma positivação tardia das práticas já existentes no governo Vargas. As leis, posteriormente, tentavam dar um ar de legalidade às ações inconstitucionais praticadas pelo governo Vargas e subsidiadas pelos Tribunais: não existia Estado de Direito, não existia Constituição, não existia cidadania, existia violência e Estado de exceção.

Segundo Loewenstein (1944), a positivação do TSN possibilitava que os juízes julgassem os casos baseados apenas por livre convicção, ou seja, os magistrados não estavam vinculados a reduzidas regras formais, nas quais o sistema jurídico brasileiro era baseado:

This means in practice, that they have the right to take evidence as they see fit and to interpret it as they see fit, without being bound by any formalized rules or binding precedents which under Roman Law system do not exist anyway. (LOEWENSTEIN, 1944, p. 218). 
O TSN era um tribunal a serviço do governo: o anuário estatístico do Brasil publicado em 1941 demonstra que em 1937 foram julgados 374 acusados pelo TSN. Após o Estado Novo, em 1938, 3049. (IBGE, 1941). A sociedade estava ciente dessa violência e Graciliano Ramos em Memórias do Cárcere pode muito bem expor esse sentimento quando descreve o teatro, a comédia que os presos fizeram sobre o TSN. Os presos descrevem um julgamento, um teatro que é feito dentro do presídio, sobre o TSN:

Primeiro os Juízes que gritam ao acusado: "Defenda-se", "Defenda-se, covarde" (RAMOS, 2008, p. 647). O "canalha" não se defende e é necessário escolher um “patrono razoável” (RAMOS, 2008, p. 647).

E Ivan Ribeiro surgiu, chegou-se ao réu, entabulou um discurso em linguagem profundamente revolucionária, sem nenhuma deferência aos magistrados. Jogou em cima deles pedaços do programa da Aliança Nacional Libertadora e frases que diariamente se renovavam para animar os espíritos vacilantes. Pão, terra e liberdade. [...] Foi pouco além do intróito. Logo aos primeiros arremessos, os julgadores alarmaram-se, arrepiaram-se como se os mordessem pulgas: entenderam-se à pressa, com visível receio de que tais desconchavos fossem ouvidos lá fora. [...] O inconveniente defensor prosseguiu [...]. (RAMOS, 2008, p. 648).

Mas lembrou o funcionário: "É outro advogado que vem patrocinar a causa deste miserável" (RAMOS, 2008, p. 649). E, obviamente, o primeiro advogado, que não agradou ao Tribunal, é substituído. Após, discursa, o novo procurador:

Eu nem preciso examinar o processo, pois este caso é notório. $\mathrm{O}$ réu não esconde seus crimes. Atentou contra as nossas instituições, conspirou, usou bombas e combateu as forças legais - todo mundo sabe. [...] Além disso, devemos reconhecer, temos diante de nós um irresponsável. É um infeliz, um pobre-diabo, ruína física. Pela cara vemos perfeitamente: um imbecil, um idiota. Sem dúvida obedeceu às instruções dos agentes de Moscou. Assim, venerandos juízes, não venho pedir justiça, que este individuo é um canalha - todo o mundo sabe. Espero clemência, e baseio-me nas tradições miseri- 
cordiosas da nossa cultura ocidental. Uma pena suave, meritíssimos juízes, aí uns trinta anos [...]. (RAMOS, 2008, p. 649-650).

O Tribunal foi misericordioso: “Apenas trinta anos, na ilha Grande. Uma sentença módica” (RAMOS, 2008, p. 650). Todos concordam e os juízes retiram-se. Termina o teatro e todos riem.

Todos sabiam: não existia possibilidade de absolvição, defesa ou contraditório. A condenação era dirigida a todos os acusados que se levantavam contra o governo Vargas. Juízes, promotores, advogados, todos eram atores no teatro do TSN.

Não estamos aqui para discutir. Temos superiores, eles pensarão por nós.

[...]

As cortinas cerraram-se. A platéia ria. Na saleta do café, os guardas riam. (RAMOS, 2008, p. 96 - 650).

\section{5. É Possível Tirar Conclusões?}

Perde-se tempo precioso no estudo de aspectos muito pretéritos e distantes da história da normatividade, deixando-se de lado a análise de casos realmente eloqüentes, como o presente (referindo-se ao caso de Genny Gleiser) que denuncia época perversa, maniqueísta, chauvinista, racista e machista. E boa parte do direito e dos autores que digerimos são frutos daquele tempo. (GODOY, 2008, p. 111).

Talvez seja o momento de se pensar um projeto de país, consciente da sua história e dos caminhos que já foram percorridos. Talvez seja o momento da história do Direito voltar seus olhos para o Brasil e perceber quão importante é contribuir para uma compreensão da sociedade e do direito atual. Sem uma história do direito plural, crítica, interdisciplinar e para além do direto positivo, o grande problema é o da repetição dos erros e das violências, o grande problema é o esquecimento do que somos e 
de onde viemos e de que experiências, conscientes ou inconscientes, submergem na nossa cultura jurídica.

\section{Referências}

BALZ, Christiano Celmer. O Tribunal de Segurança Nacional: Aspectos legais e doutrinários de um tribunal na Era Vargas (1936-1945). 2009. 228f. Dissertação (Mestrado em Direito) - Faculdade de Direito, Universidade Federal de Santa Catarina, Florianópolis, 2010.

BRASIL. Lei $n$. 38, de 4 de abril de 1935. Define crimes contra a ordem política e social. Disponível em: $<$ http://www2.camara.gov.br/legin/fed/ lei/1930-1939/lei-38-4-abril-1935-397878-repuplicacao-77367-pl.html>. Acesso em: 11 jan. 2011.

. Lei n. 136, de 14 de dezembro de 1935. M odifica vários dispositivos da Lei n. 38, de 4 de abril de 1935 e define novos crimes contra a ordem político social. Disponível em: <http://www2.camara.gov. br/legin/fed/lei/1930-1939/lei-136-14-dezembro-1935-398009-norma-pl. html>. Acesso em: 11 jan. 2011.

. Lei n. 244. de 11 de setembro de 1936. Institue, como orgão da Justiça Militar, o Tribunal de Segurança Nacional, que funcionará no Distrito Federal sempre que for decretado o estado de guerra e dá outras providências. Disponível em: < http://www2.camara.gov.br/legin/ fed/lei/1930-1939/lei-244-11-setembro-1936-503407-norma-pl.html>. Acesso em: 11 jan. 2011.

. Constituições Brasileiras: 1934. v. 3. Brasília: Senado Federal, Ministério da Ciência e Tecnologia, Centros de Estudos Estratégicos, 2001a.

. Constituições Brasileiras: 1937. v. 4. Brasília: Senado Federal, Ministério da Ciência e Tecnologia, Centros de Estudos Estratégicos, 2001b.

CARVALHO, José Murilo de. Cidadania no Brasil: o longo caminho. 10. ed. Rio de Janeiro: Civilização Brasileira, 2008. 
DULLES, John W.F. Sobral Pinto: A consciência do Brasil - A cruzada contra o regime Vargas 1930 - 1945. Tradução Flávia Mendonça Araripe. Rio de Janeiro: Nova Fronteira, 2001.

FAUSTO, Boris. História do Brasil. 7. ed. São Paulo: Edusp, 2008.

GODOY, Arnaldo Sampaio de Moraes. A História do Direito entre foices, martelos e togas: Brasil - 1935-1965. São Paulo: Quartier Latin, 2008.

IBGE - INSTITUTO BRASILEIRO DE GEOGRAFIA E ESTATÍSTICA. Anuário Estatístico do Brasil-Ano V-1939-1940. Rio de Janeiro: IBGE, 1941.

LOEWENSTEIN, Karl. Brazil under Vargas. New York: Macmillan Company, 1944.

MORAES, Dênis de; VIANA, Francisco. Prestes: lutas e autocríticas. Rio de Janeiro: Mauad, 1997.

MOTTA, Rodrigo Patto Sá. Corrupção no Brasil Republicano - 19541964. In: AVRITZER, Leonardo; BIGNOTTO, Newton; GUIMARÂES, Juarez; STARLING, Heloísa Maria Murgel (Orgs.) Corrupção: ensaios e críticas. Belo Horizonte: UFMG, 2008.

RAMOS, Graciliano. Memórias do Cárcere. 44. ed. São Paulo: Record, 2008.

Recebido em: 25/11/2010

Revisado em: 06/12/2010

Aprovado em: 15/12/2010 